в групі МА виявлено, що найнижчі показники СВ та $\mathrm{DO}_{2}$ спостерігаються на 3-му етапі під час індукції анестезії та насиченні IA. Але показник $\mathrm{DO}_{2}$ на 3-му етапі статистично достовірно (р <0,0011) нижче в групі МА порівняно з групою ПА (на перших 2-х етапах статистично значуща різниця між підгрупами відсутня). Ми вважаємо таку різницю впливом індукції севофлурану на гемодинаміку та більш інтенсивні параметри початкового FGF на етапі індукції в групі МА порівняно з групою ПА.

На 4-му етапі в групі ПА відмічено підвищення

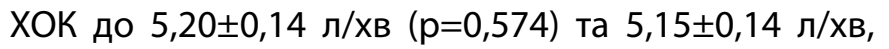

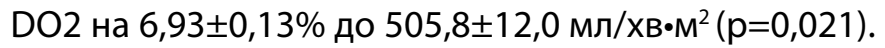
На 4-му етапі в групі МА відмічено поступове статистично достовірне ( $p<0,01)$ підвищення СВ

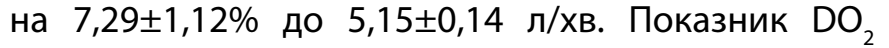
також статистично достовірно (р <0,01) зростав на 8,42 $0,21 \%$ порівняно 3 попереднім етапом та становив 480,6 $\pm 10,2$ мл/хв•м2.

На 5-му етапі, як найбільш агресивному етапі оперативноговтручання,намивідміченопідвищення

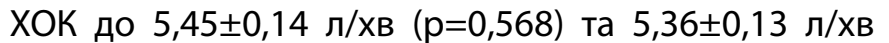
$(p=0,534)$ в групах ПА та МА відповідно, DO 2 зростає

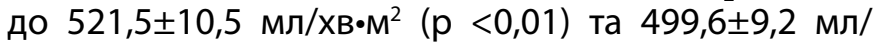
хв•м² в групах ПА та МА відповідно, різниця між групами достовірна. Зберігається статистично достовірна різниця між підгрупами ПА та МА на 5-му та 6-му етапах за показниками DO2. Таким чином, застосування початкового $F G F=2000$ мл/хв та IMПА з FGF=400 мл/хв при базовій IA в групі ПА меншою мірою знижує $\mathrm{DO}_{2}$ у порівнянні з $\mathrm{FGF}=4000$ мл/хв та IHПА з FGF=500-700 мл/хв в групі МА. На 7-му етапі між групами не відмічено статистично достовірної різниці за $\mathrm{DO}_{2}(\mathrm{p}>0,05)$.

\section{Висновки}

1. IA севофлураном має негативний вплив на показники гемодинаміки. Найбільша депресія показників гемодинаміки (АТс, АТд, СрАТ. ПТ, ХOK, Cl, 3ПСО) відмічена на 3-му етапі - після ввідної анестезії та інтубації трахеї та початку базової анестезії. На 4-7 етапах було відмічено стабілізацію параметрів АТс, АТд, СрАТ, чСС. Не відмічено відстроченого негативного впливу севофлурану на показники системної гемодинаміки.

2. На 4-6 етапах найвищі показники $\mathrm{DO}_{2}$ відмічені в групі ПА, які мали статистичну достовірність 3 групою МА. Застосування початкового $F G F=2000$ мл/ хв та IMПА з FGF=400 мл/хв при базовій IA в групі ПА меншою мірою знижує $\mathrm{DO}_{2}$ у порівнянні з $\mathrm{FGF}=4000$ мл/хв та IHПА з FGF=500-700 мл/хв в групі МА.

Ключові слова: синдром тиреотоксикозу, доставка кисню, гемодинаміка.

\section{ЛІТЕРАТУРА}

1. Marino, P. (2014). Marino's the ICU book: 4th edition. Philadelphia (PA): Lippincott Williams \& Wilkins, 1041.

2. Watson, X., Cecconi, M. (2017). Haemodynamic monitoring in the peri-operative period: the past, the present and the future. Anaesthesia, 72, 7-15. doi:10.1111/anae.13737.

3. Osuna, P.M., Udovcic, M., \& Sharma, M.D. (2017). Hyperthyroidism and the Heart. Methodist DeBakey Cardiovascular Journal, 13(2), 60-63. http://doi. org/10.14797/mdcj-13-2-60.

\title{
ДИАГНОСТИЧЕСКАЯ ЦЕННОСТЬ ОТДЕЛЬНЫХ ЛАБОРАТОРНЫХ ПОКАЗАТЕЛЕЙ В ДИАГНОСТИКЕ СУБКЛИНИЧЕСКОГО СИНДРОМА КУШИНГА У ПАЦИЕНТОВ С АРТЕРИАЛЬНОЙ ГИПЕРТЕНЗИЕЙ
}

\author{
Е.Э. Третьяк, Л.В. Щекатурова, С.М. Черенько \\ Украинский научно-практический иентр эндокринной хирургии, трансплантации \\ эндокринных органов и тканей МОЗ Украины, г. Киев
}

\begin{abstract}
Своевременная диагностика и лечение гиперкортизолемии. Когортные исследования субклинического варианта синдрома Кушинга подтверждают, что распространенность АГ (СК), одним из проявлений которого является среди пациентов с гиперкортицизмом выше, артериальная гипертензия (АГ), позволяет и увеличивается с периодом наблюдения [1]. остановить прогрессирующие последствия скрытой Вторичная артериальная гипертензия обратима
\end{abstract}


при излечении СК в 75\% случаев [2]. Все это подтверждает обоснованность своевременного выявления гормонального избытка у пациентов групп риска. Определение диагностической ценности лабораторных показателей, используемых для диагностики СК, является частью исследования распространенности субклинического синдрома Кушинга среди пациентов групп риска, выполненного на базе УНПЦЭХ.

Материалы и методы. В исследование включено 390 пациентов - пациенты с избыточной массой тела, артериальной гипертензией, нарушением углеводного обмена, инциденталомами надпочечника. Группу пациентов с АГ в качестве ведущего клинического синдрома составляло 140 человек - 84 (59,9\%) женщин и 56 (40,1\%) мужчин. Исследование включало 2 этапа: на первом пациентам определяли кортизол сыворотки на фоне ночной дексаметазоновой пробы, с пороговым значением исключения СК <1,8 мкг/дл; на втором этапе выполнялись анализы суточной экскреции свободного кортизола, уровня АКТГ плазмы утром, дигидроэпиандростерон-сульфата (ДГТА) сыворотки. Диагностическую ценность определяли с помощью ROC (Receiver Operating Characteristic) c построением соответствующих характеристических кривых и с расчетом площади под кривыми (Area UndertheCurve-AUC), согласнопоказателямкоторой оценивали качество модели. Наибольшее значение AUC характеризовало наивысшую диагностическую ценность показателя (оптимальное соотношение между чувствительностью и специфичностью по отношению к исследованному явлению).

Результаты. Субклинический СК подтвержден у 8 пациентов (5,7\%). Наиболее информативный диагностический тест - ночная дексаметазоновая проба с пороговым значением cut-off point (COP) 2,04 мкг/дл. Диагностическая ценность определялась с помощью корреляционного анализа, результат которого подтверждает, что кортизол на фоне overnight test является лучшим показателем - при СОР 2,04 мкг/дл демонстрирует чувствительность 100\%, специфичность $66 \%$. Уровень АКТГ плазмы натощак обозначен вторым по значимости лабораторным тестом с пороговым значением СОР 8,5 пг/мл. При этом прогностически качественной диагностической моделью может быть признан только уровень АКТГ, с обратной зависимостью - чем ниже уровень АКТГ, тем выше вероятность наличия СК. Пороговое значение
(СОР) 8,5 пг/мл, чувствительность в точке деления 55,6\%, специфичность - 90,5\%. AUC - 0,722, $\mathrm{p}=0,014$. Показатель ДГТА-сульфат сыворотки демонстрировал высокую специфичность (79\%), но имел более низкую чувствительность (42,9\%), при этом СОР во всех случаях составлял показатель ниже референтных значений для пола и возраста в каждом отдельном случае, но обозначен авторами как второй по значимости, после АКТГ, в качестве критерия, подтверждающего автономную продукцию кортизола аденомой надпочечника. Показатель суточной экскреции свободного кортизола обладает низкой информативностью при скрининге пациентов с субклиническим СК - специфичность 30\% при СОР 475,3 мкг/24 часа, вследствие большого количества ложноположительных результатов. Полученные данные подтверждают результаты исследований других авторов [3, 4].

Выводы. Скрытая гиперкортизолемия может быть выявлена при скрининге у 5,7\% пациентов с артериальной гипертензией. Наиболее информативным диагностическим тестом является ночная дексаметазоновая проба. Уровень АКТГ крови является вторым по значимости лабораторным тестом с рациональным применением порогового уровня в 8,5 пг/мл. Показатель суточной экскреции свободного кортизола обладает низкой информативностью при скрининге пациентов с субклиническим СК.

Ключевые слова: субклинический синдром Кушинга. кортизол, ночная дексаметазоновая проба, АКТГ, артериальная гипертензия.

\section{ЛИТЕРАТУРА}

1. Carey R.M. Overview of Endocrine Systems in Primary Hypertension // Endocrinol Metab Clin North Am. 2011. - Vol. 40, N. 2. - P. 265-277.

2. Gary L., Schwartz M. Screening for AdrenalEndocrine Hypertension: Overview of Accuracy and Cost-effectiveness // Endocrinol. Metab. Clin. North. Am. - 2011. - Vol. 40, N. 2. - P. 279-294.

3. Starker LF, Kunstman JW, Carling T. Subclinical Cuching Syndrom: a Review // Surg. Clin. North. Am. - 2014. - Vol. 94. - P. 657-668.

4. Dralle H., Newell-Price J., Tabarin A., et al. Management of adrenal incidentalomas: European Society of Endocrinology Clinical Practice Guideline in collaboration with the European Network for the Study of Adrenal Tumors // Eur J. Endocrinol. - 2016. - Vol. 175, N. 2. - P. 1-34. 